\title{
Anticonvulsants in the treatment of low back pain and lumbar radicular pain: a systematic review and meta-analysis
}

\author{
Oliver Enke MBBS MSc, Heather A. New MBBS MPH, Charles H. New MBBS, Stephanie Mathieson PhD, Andrew \\ J. McLachlan PhD, Jane Latimer PhD, Christopher G. Maher PhD, C.-W. Christine Lin PhD
}

Cite as: CMAJ 2018 July 3;190:E786-93. doi: 10.1503/cmaj.171333

\begin{abstract}
BACKGROUND: The use of anticonvulsants (e.g., gabapentin, pregabalin) to treat low back pain has increased substantially in recent years despite limited supporting evidence. We aimed to determine the efficacy and tolerability of anticonvulsants in the treatment of low back pain and lumbar radicular pain compared with placebo.
\end{abstract}

METHODS: A search was conducted in 5 databases for studies comparing an anticonvulsant to placebo in patients with nonspecific low back pain, sciatica or neurogenic claudication of any duration. The outcomes were self-reported pain, disability and adverse events. Risk of bias was assessed using the Physio- therapy Evidence Database (PEDro) scale, and quality of evidence was assessed using Grading of Recommendations Assessment, Development and Evaluation (GRADE). Data were pooled and treatment effects were quantified using mean differences for continuous and risk ratios for dichotomous outcomes.

RESULTS: Nine trials compared topiramate, gabapentin or pregabalin to placebo in 859 unique participants. Fourteen of 15 comparisons found anticonvulsants were not effective to reduce pain or disability in low back pain or lumbar radicular pain; for example, there was high-quality evidence of no effect of gabapentinoids versus placebo on chronic low back pain in the short term (pooled mean difference [MD] -0.0 , $95 \%$ confidence interval $[\mathrm{Cl}]-0.8$ to 0.7 ) or for lumbar radicular pain in the immediate term (pooled MD -0.1, 95\% Cl -0.7 to 0.5 ). The lack of efficacy is accompanied by increased risk of adverse events from use of gabapentinoids, for which the level of evidence is high.

INTERPRETATION: There is moderate- to high-quality evidence that anticonvulsants are ineffective for treatment of low back pain or lumbar radicular pain. There is high-quality evidence that gabapentinoids have a higher risk for adverse events. Protocol registration: PROSPERO-CRD42016046363
M

illions of people have low back pain, which causes more disability than any other health condition. ${ }^{1}$ Most people with low back pain have symptoms resulting from nonspecific causes. About $5 \%$ to $10 \%$ of people with low back pain have sciatica, ${ }^{2}$ in which the leg pain follows the sciatic nerve and can be accompanied by strength, sensory and reflex changes in the leg. ${ }^{3} \mathrm{~A}$ smaller proportion of people have neurogenic claudication, in which the leg pain is associated with spinal stenosis and symptoms are exacerbated with extension activities (e.g., walking) and relieved by flexion (e.g., sitting). ${ }^{4}$ Leg pain originating from the lumbar spine is commonly referred to as radicular pain..$^{5}$

Clinical guidelines on the treatment of low back pain generally recommend nonpharmacologic interventions and nonopioid analgesics, ${ }^{6,7}$ rather than stronger analgesics such as anticonvulsants. ${ }^{6} \mathrm{How}-$ ever, the increasing use of anticonvulsant medicines in patients with low back pain has been reported. ${ }^{8}$ Such an increase could be justified if these drugs relieve symptoms and the benefits outweigh harms. The latter is important, as recent reports point to an increased risk of suicidality ${ }^{9}$ and the potential for misuse ${ }^{10,11}$ of some anticonvulsants.

The analgesic action of anticonvulsant medicines is thought to be a result of limiting neuronal excitation and enhancing inhibition. ${ }^{12}$ Anticonvulsant medicines such as gabapentin and pregabalin, sometimes called gabapentinoids, have been shown to be effective in neuropathic pain conditions such as diabetic peripheral neuropathy. ${ }^{13}$ However, the evidence for the efficacy and safety of anticonvulsants in low back and lumbar radicular pain is unclear and can be resolved only by high-quality evidence produced from placebo-controlled trials. Previous reviews were limited only to populations with chronic back pain, ${ }^{14}$ and new evidence may affect conflicting and limited conclusions. ${ }^{5,15}$ Therefore, this systematic review aimed to determine the efficacy and tolerability of anticonvulsants in the treatment of low back pain and lumbar radicular pain compared with placebo. 


\section{Methods}

\section{Study registration}

A protocol was prospectively registered on the International Prospective Register of Systematic Reviews (PROSPERO; CRD42016046363).

\section{Search strategy and study inclusion}

We performed electronic database searches on MEDLINE, Embase, CINAHL, PsycINFO, the Cochrane Central Register for Controlled Trials (CENTRAL) and the WHO International Clinical Trials Registry Platform from inception to December 2017.

We searched for randomized parallel and crossover controlled trials investigating the effects of anticonvulsants in adults with nonspecific low back pain with or without radiating leg pain, sciatica or neurogenic claudication secondary to lumbar spinal stenosis of any duration. We excluded studies investigating pain in pregnancy or after surgery. Studies of participants with mixed conditions (e.g., low back and neck pain) were also excluded, unless the results were reported separately or were obtained from authors.

To be eligible, studies had to compare an anticonvulsant (as classified by the World Health Organization (WHO) Collaborating Centre for Drug Statistics Methodology, N03A Antiepileptics) $)^{16}$ to placebo, and report any outcome of pain intensity (e.g., numerical rating scale), disability (e.g., Roland-Morris Disability Questionnaire) or adverse events. The anticonvulsant intervention was to be administered in primary care via any route (e.g., oral, topical, intravenous injection), without imaging assistance or extended time for administration (e.g., intravenous infusion). The protocol allowed active control (e.g., another pharmacologic intervention), but the current report is limited to placebo comparisons only, to focus on efficacy. Comparative effectiveness trials comparing 2 active drug treatments of unknown efficacy provide ambiguous results, as it is not possible to establish whether the winning drug is the least harmful of the 2 or the most effective of the 2 .

We developed a search strategy using keywords for randomized controlled trials (RCTs) and low back pain or sciatica published by the Cochrane Back and Neck Group, ${ }^{17}$ plus keywords to identify anticonvulsants based on a recent Cochrane review ${ }^{18}$ and the WHO Collaborating Centre for Drug Statistics Methodology Anatomical Therapeutic Chemical (ATC) classification of antiepileptics ${ }^{16}$ (Appendix 1, available at www.cmaj.ca/lookup/suppl/doi:10.1503/cmaj.171333/-/DC1). There was no language or publication restriction. We contacted the principal authors of unpublished studies for more information if eligibility was unclear, and searched reference lists of included trials and related systematic reviews to identify potentially relevant studies.

Title and abstract screening was performed by 1 reviewer (O.E.), and an independent reviewer was consulted if there were any uncertainties. Two reviewers (O.E., H.A.N.) independently screened full-text articles for eligibility. Disagreements were resolved by discussion first, then arbitration by a third, independent reviewer (C.G.M.).

\section{Data extraction and risk of bias assessment}

We used standardized and piloted data extraction forms to record the characteristics of the participants, intervention and outcomes. Two reviewers extracted the data (2 of O.E., H.A.N. or
C.-W.C.L.). Reviewers did not assess any study to which they had contributed. Disagreements were resolved by discussion first, then arbitration by an independent reviewer (C.H.N.) if needed. For crossover trials, we planned to confine data extraction to the pre-crossover data to avoid a potential carryover effect. However, this was not possible, owing to the lack of data; therefore, we took all measurements from the anticonvulsant and placebo periods and analyzed these as if the trial was a parallel group trial of anticonvulsant versus placebo. ${ }^{19}$ We accounted for the risk for a carryover effect secondary to a crossover design when assessing the quality of the evidence by downgrading 1 level.

For pain and disability outcomes, we extracted data at these time points: immediate ( $\leq 2 \mathrm{wk}$ after randomization), short $(>2 \mathrm{wk}$ but $\leq 3 \mathrm{mo})$, intermediate $(>3$ but $<12 \mathrm{mo}$ ) and long $(\geq 12 \mathrm{mo}$ ) term. If multiple time points were reported within 1 follow-up period, we used the time closest to 2 weeks, 7 weeks, 6 months and 12 months for each follow-up period, respectively. For safety outcomes, we extracted the number of participants with any serious adverse events and adverse events over the course of the study.

Two reviewers (O.E., H.A.N.) independently assessed the risk of bias of individual studies using the 11-item Physiotherapy Evidence Database (PEDro) scale, ${ }^{20,21}$ with disagreements resolved by consensus. The PEDro scale is widely used and has been shown to be a valid and reliable tool for assessing the risk of bias of clinical and pharmacologic trials. ${ }^{21}$ It shows a high positive correlation $(0.83,95 \%$ confidence interval $[\mathrm{Cl}] 0.76$ to 0.88$)$ with the Cochrane Risk of bias tool. ${ }^{21}$ Its items show no redundancy; therefore, it is valid to combine the items to obtain a total PEDro score as a measure for risk of bias. ${ }^{22}$

\section{Statistical analysis}

For pain and disability outcomes, included studies were grouped first by the type of pain (nonspecific low back pain or lumbar radicular pain), then by anticonvulsant medicine, outcome and follow-up time point. Lumbar radicular pain included sciatica and neurogenic claudication secondary to lumbar spinal stenosis. Anticonvulsant medicines with similar modes of action were grouped together; e.g., gabapentin and pregabalin. ${ }^{23}$ Where appropriate, data were pooled and treatment effects were quantified using mean differences (MDs; if the same scale was used) or standardized mean differences (SMDs; if different scales were used) for continuous outcomes (pain and disability) using a random-effects model, and risk ratios for dichotomous outcomes (adverse events). We considered a between-group difference of $10 \%$ or more on the scale used for pain or disability to be clinically worthwhile. ${ }^{24}$ For safety outcomes, we grouped the included studies by the anticonvulsant medicine only. We conducted the analysis using Comprehensive Meta-Analysis V3 (Biostat, Englewood, NJ).

\section{Assessment of heterogeneity}

We assessed clinical and methodological heterogeneity and undertook pooling if heterogeneity was acceptable (e.g., $I^{2}<$ $75 \%)^{19}$ using a random-effects model. Clinical and methodological heterogeneity was also considered when grading the level 
of evidence (Appendix 2, available at www.cmaj.ca/lookup/suppl/ doi:10.1503/cmaj.171333/-/DC1).

\section{Grading of evidence}

We assessed the overall quality of evidence using a Grading of Recommendations Assessment, Development and Evaluation (GRADE) approach, ${ }^{25}$ which considered study design, risk of bias, imprecision and inconsistency. We did not assess publication bias and indirectness, as there were insufficient studies and all studies were of the population of interest. The quality of evidence was downgraded by 1 or 2 levels for each domain, depending on whether a serious or a very serious flaw was present (Appendix 2). GRADE was applied in panel discussions and consensus was used to resolve any disagreement.

\section{Results}

The search resulted in 1240 records, of which 93 full-text articles were assessed. Common reasons for exclusion after full-text screening were related to the study design or population (Figure 1). Nine eligible studies were included, with a total of 859 participants (Table 1 ). ${ }^{26-34}$ The average age of participants was 50.8 years (range 38.0 to $71.1 \mathrm{yr}$ ) in the treatment group and 51.5 years (range 24.0 to $74.0 \mathrm{yr}$ ) in the placebo group. Six trials were RCTs 26,27,30,32-34 $^{2}$ and 3 were randomized crossover trials ${ }^{28,29,31}$ for which pre-crossover results were not reported. All but 1 trial ${ }^{28}$ had low risk of bias (PEDro scale $\geq 7$, Appendix 3, available at www.cmaj.ca/lookup/suppl/ doi:10.1503/cmaj.171333/-/DC1), but 3 studies had a dropout rate of greater than $15 \% .{ }^{29,33,34}$ There was near-perfect agreement between reviewers (O.E., H.A.N.) on the risk of bias assessment, with only 4 of 99 items (4\%) requiring discussion and a consensus decision.

Four trials recruited participants with chronic low back pain with or without radiating leg pain, ${ }^{26,31-33}$ and 5 trials recruited participants with lumbar radicular pain (4 in sciatica, ${ }^{27,28,30,34} 1$ in neurogenic claudication $\left.{ }^{29}\right)$. Only 1 trial included participants with acute symptoms $(<3 \mathrm{mo}) .{ }^{30}$ Three trials confirmed participant lumbar spine pathology radiographically (Appendix 4, available at www.cmaj.ca/lookup/suppl/ doi:10.1503/cmaj.171333/-/DC1)..$^{28,29,34}$ The mean treatment duration was 6.7 weeks (range $10 \mathrm{~d}$ to $12 \mathrm{wk}$ ). The anticonvulsants investigated were gabapentinoids (pregabalin $27,29,30$ or gabapentin ${ }^{26,31,32,34}$ ) and topiramate. ${ }^{28,33}$ Most studies applied selfreported numerical pain-rating scales (NPRSs), ${ }^{26,28-32,34}$ and 1 used a descriptor- based pain rating index..$^{33}$ Disability was reported using either the Oswestry Disability Index $26,28,29,33$ or Roland-Morris Disability Questionnaire. ${ }^{30}$ Most studies reported immediate or short-term data only.

\section{Efficacy of anticonvulsants for low back pain with or without radiating leg pain}

Three trials investigated a gabapentinoid (gabapentin) versus placebo for chronic low back pain with or without radiating leg pain. ${ }^{26,31,32}$ There was no effect for pain in the short term (pooled MD $-0.0,95 \% \mathrm{Cl}-0.8$ to 0.7 on a 0 - to 10 -point NPRS, 3 studies, Figure 2). The quality of evidence was high (Appendix 5, available at www.cmaj.ca/lookup/suppl/doi:10.1503/cmaj.171333/-/DC1) but 2 studies $^{31,32}$ investigated gabapentin below the recommended dose of $1800-3600 \mathrm{mg} / \mathrm{d} .{ }^{35}$ Similarly, there was no treatment effect for pain in the intermediate term (MD $-0.1,95 \% \mathrm{Cl}-1.4$ to 1.2 on a 0 to 10-point NPRS, 1 study) with low quality of evidence (downgraded owing to study design and imprecision). One study investigated disability in the short term only, ${ }^{26}$ and showed no treatment effect (MD $-0.2,95 \% \mathrm{Cl}-5.9$ to 5.5 on a 100-point Oswestry Disability Index) with high-quality evidence.

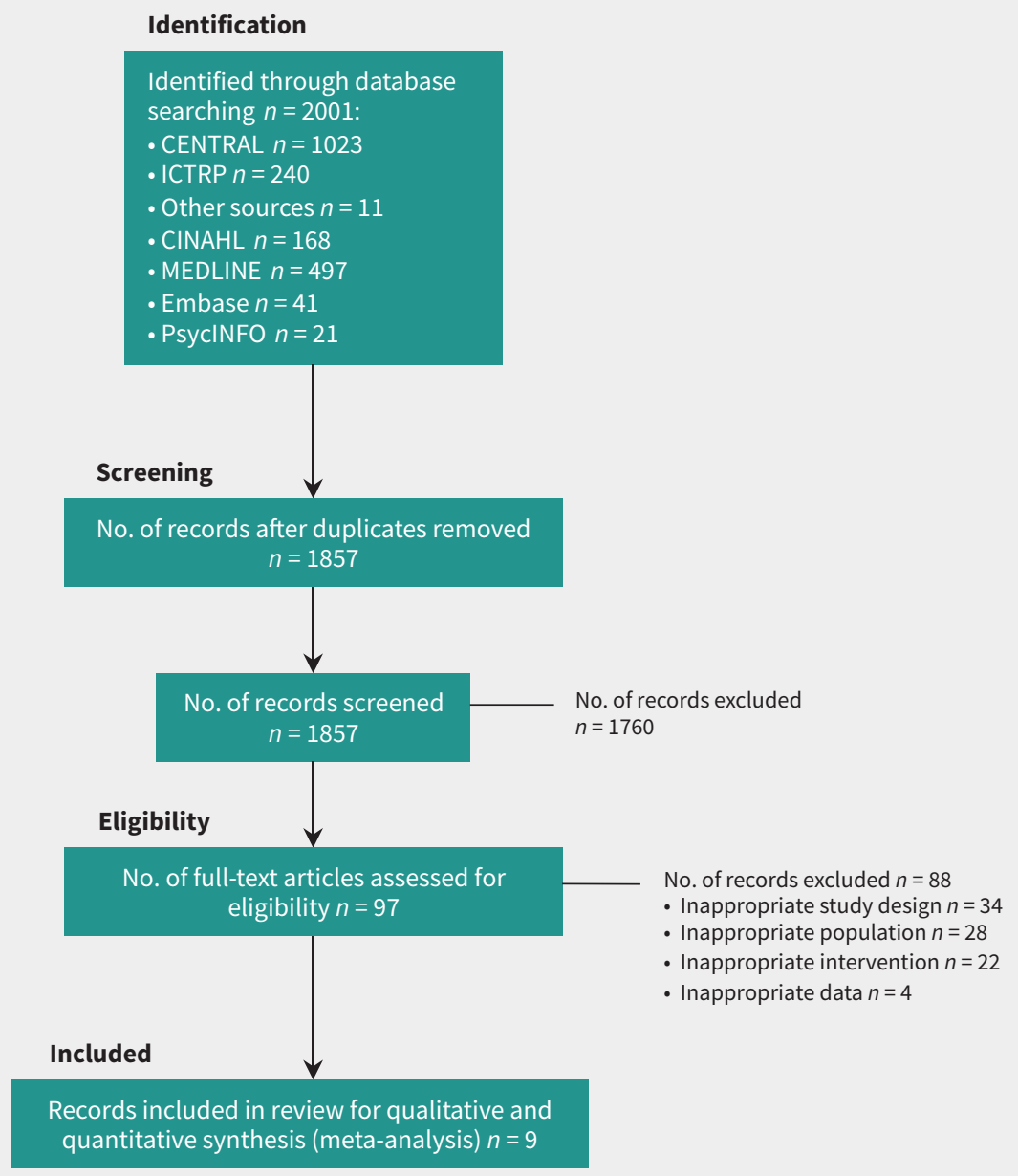

Figure 1: PRISMA flow diagram. Note: CENTRAL = Cochrane Central Register for Controlled Trials, ICTRP = International Clinical Trials Registry Platform. 
One trial investigated topiramate against placebo for chronic low back pain with or without radiating leg pain. ${ }^{33}$ There was a small, clinically worthwhile treatment effect favouring topiramate in pain in the short term (MD -11.4, 95\% $\mathrm{Cl}-16.7$ to -6.1 on a 78 -point pain scale), and no treatment effect for topiramate on disability in the short term (MD -4.9, $95 \% \mathrm{Cl}-19.4$ to 9.6 on a 100 -point Oswestry Disability Index). These findings had moderate-quality evidence, downgraded owing to imprecision.

\section{Efficacy of anticonvulsants for lumbar radicular pain}

Four studies investigated the efficacy of gabapentinoids (pregabalin or gabapentin) versus placebo in patients with lumbar radicular pain, ${ }^{27,29,30,34}$ in which 3 studies provided data for inclusion in the forest plot ${ }^{29,30,34}$ (Figure 2). There was high-quality evidence of no effect on pain in the immediate term (pooled MD $-0.1,95 \% \mathrm{Cl}-0.7$ to 0.5 on a 0 - to 10 -point NPRS, 2 studies), but short-term results of 2 studies had high heterogeneity $\left(R^{2}=95 \%\right)$ and therefore were not pooled. Whereas Yildirim and colleagues ${ }^{34}$ report pain relief with

\section{Table 1: Characteristics of studies}

\section{Study}

Atkinson et al. ${ }^{26}$

Baron et al. ${ }^{27} 217$ participants with chronic ( $\geq 3 \mathrm{mo}$ )

108 participants with chronic $(\geq 6 \mathrm{mo})$ LBP with or without radiating leg pain. Mean age \pm SD: gabapentin group $57.6 \pm$ $8.8 \mathrm{yr}$; placebo group $54.6 \pm 11.4 \mathrm{yr}$. radiculopathy. Mean age \pm SD: pregabalin group $52.5 \pm 11.1 \mathrm{yr}$; placebo group $52.6 \pm 12.8 \mathrm{yr}$.

\section{Khoromi et}

al. ${ }^{28 *}$

Markman et al. $^{29 *}$

Mathieson et al. $^{30}$

McCleane $\mathrm{B}^{3{ }^{\star}}$

80 participants with chronic LBP with or without radiating leg pain (neuropathic pain features e.g., paresthesia, excluded). Mean age \pm SD: gabapentin group $41.3 \pm 13.1 \mathrm{yr}$; placebo group $47.8 \pm 11.7 \mathrm{yr}$.

Muehlbacher 96 participants with chronic $(\geq 6 \mathrm{mo})$ et al..$^{33}$ LBP with or without radiating leg pain (excluding neurologic deficits). Mean age \pm SD: topiramate group $48.8 \pm 5.5 \mathrm{yr}$; placebo group $48.7 \pm 5.0 \mathrm{yr}$.

Yildirim et $\quad 50$ participants with chronic ( $\geq 3 \mathrm{mo}$ ) al. ${ }^{34}$ sciatica. Mean age \pm SD: gabapentin group $38.0 \pm 7.4 \mathrm{yr}$; placebo group $40.5 \pm$ $10.5 \mathrm{yr}$.

Intervention

Outcomes

Flexible dosing of gabapentin up to $3600 \mathrm{mg} / \mathrm{d}$ for $12 \mathrm{wk}$, v. matching placebo. Add-on therapy with NSAIDs permitted.

Five-phase intervention of screening, single-blind placebo, single-blind pregabalin, double-blind, then tapering. Placebo responders and pregabalin nonresponders removed before double-blind phase. In the randomized double-blind phase, pregabalin dose was the individual optimal dose determined in single-blind phase (maximum $600 \mathrm{mg} / \mathrm{d}$ ), for $6 \mathrm{wk}$ v. matching placebo. Add-on therapy not allowed.

Flexible dosing up to $400 \mathrm{mg} / \mathrm{d}$ of topiramate for $6 \mathrm{wk} \mathrm{v}$. active placebo (flexible dosing of diphenhydramine up to $50 \mathrm{mg} / \mathrm{d}$ ) for $8 \mathrm{wk}$.

Flexible dosing of pregabalin up to $300 \mathrm{mg} / \mathrm{d}$ or diphenhydramine of $25 \mathrm{mg} / \mathrm{d}$ for $13 \mathrm{~d}$. Seven-day washout between crossover periods. Other analgesic (other than gabapentin) permitted if stable at baseline.

Flexible dosing of pregabalin up to $600 \mathrm{mg} / \mathrm{d}$ for $\leq 8 \mathrm{wk}, \mathrm{v}$. matching placebo. Add-on analgesic therapy permitted.

Flexible dosing of gabapentin titrated in $300 \mathrm{mg}$ increments weekly to maximum $15 \mathrm{mg} / \mathrm{kg} / \mathrm{d}$ for $6 \mathrm{wk}$ v. placebo. Seven-day washout between crossover periods. Add-on therapy with NSAIDs or paracetamol plus codeine combination permitted.

Fixed titration of gabapentin up to $1200 \mathrm{mg} / \mathrm{d}$ over 6 wk v. placebo, after 2-wk baseline washout. Add-on analgesia permitted.

Fixed titration of topiramate, titrated from $50 \mathrm{mg} / \mathrm{wk}$ to $300 \mathrm{mg} / \mathrm{d}$ by wk 6 then remained for $4 \mathrm{wk}$, v. placebo. Add-on therapy not permitted.

Flexible dosing of gabapentin from $900 \mathrm{mg} /$ day to up to $3600 \mathrm{mg} /$ day for $8 \mathrm{wk}$, versus placebo. Add-on therapy not permitted.
Pain, disability and adverse events at wk $1-5$, 7,9 and 12 .

Pain, disability and adverse events at wk 1-6, 8,10 and 11 .

Pain, disability and adverse events at end of crossover periods (wk 10 and 18).

Pain, disability and adverse events at 15 -second increments during exercise and at $\mathrm{d} 4$, 5, 11, 13 and 14.

Pain, disability and adverse events at wk 2, 4, $8,12,26$ and 52.

Pain and adverse events at wh 1 to 6 of both crossover periods.

Pain and adverse events at wk 8 .

Pain, disability and adverse events at wk 1 to 10 .

Pain and adverse events at wk 4 and 8 .

Note: $\mathrm{LBP}=$ low back pain, NSAIDs = nonsteroidal anti-inflammatory drugs, SD = standard deviation

${ }^{*}$ Crossover trial. 


\begin{tabular}{|c|c|c|c|c|c|c|c|c|c|c|c|}
\hline \multirow[b]{2}{*}{ Study } & \multirow[b]{2}{*}{ Drug name } & \multirow[b]{2}{*}{ Symptoms } & \multicolumn{2}{|c|}{ Anticonvulsant } & \multicolumn{2}{|c|}{ Placebo } & \multirow[b]{2}{*}{$\begin{array}{c}\text { Weight, } \\
\%\end{array}$} & \multirow{2}{*}{$\begin{array}{l}\text { Standardized } \\
\text { mean difference } \\
(95 \% \mathrm{Cl})^{\star}\end{array}$} & \multirow[b]{2}{*}{$\longleftarrow$} & \multirow[b]{2}{*}{$\begin{array}{r}\text { Favours } \\
\text { anticonvulsant }\end{array}$} & \multirow[b]{2}{*}{$\begin{array}{l}\text { Favours } \\
\text { placebo }\end{array}$} \\
\hline & & & $\begin{array}{l}\text { No. of } \\
\text { patients }\end{array}$ & Mean \pm SD & $\begin{array}{c}\text { No. of } \\
\text { patients }\end{array}$ & Mean \pm SD & & & & & \\
\hline \multicolumn{12}{|c|}{ Gabapentinoids versus placebo } \\
\hline \multicolumn{12}{|c|}{ Low back pain with or without radiating leg pain } \\
\hline Atkinson et al. ${ }^{26}$ & $\begin{array}{l}\text { Gabapentin } \\
(3600 \mathrm{mg} / \mathrm{d})\end{array}$ & $\begin{array}{l}\text { Pain§/ } \\
\text { short term }\end{array}$ & 43 & $4.1 \pm 2.3$ & 39 & $3.5 \pm 2.3$ & 40 & $0.3(-0.2$ to 0.7$)$ & & & \\
\hline McCleane $e^{31} \dagger$ & $\begin{array}{l}\text { Gabapentin } \\
(15 \mathrm{mg} / \mathrm{kg})\end{array}$ & $\begin{array}{c}\text { Pain§/ } \\
\text { short term }\end{array}$ & 24 & $6.4 \pm 2.5$ & 24 & $7.1 \pm 2.3$ & 26 & $-0.3(-0.9$ to 0.3$)$ & & & \\
\hline McCleane $^{32}$ & $\begin{array}{l}\text { Gabapentin } \\
(1200 \mathrm{mg} / \mathrm{d})\end{array}$ & $\begin{array}{c}\text { Pain\$/ } \\
\text { short term }\end{array}$ & 31 & $6.3 \pm 2.1$ & 34 & $6.5 \pm 2.1$ & 34 & $-0.1(-0.6$ to 0.4$)$ & & & \\
\hline \multicolumn{3}{|c|}{ Pooled effect: $I^{2}=25 \%$} & & & & & 100 & $0.0(-0.3$ to 0.3$)$ & & & \\
\hline McCleane $^{31} \dagger$ & $\begin{array}{r}\text { Gabapentin } \\
(15 \mathrm{mg} / \mathrm{kg})\end{array}$ & $\begin{array}{c}\text { Pain§/ } \\
\text { intermediate term }\end{array}$ & 24 & $6.9 \pm 2.2$ & 24 & $7.1 \pm 2.3$ & & $0.0(-0.6$ to 0.5$)$ & & & \\
\hline Atkinson et al. ${ }^{26}$ & $\begin{array}{l}\text { Gabapentin } \\
(3600 \mathrm{mg} / \mathrm{d})\end{array}$ & $\begin{array}{l}\text { Disabilityt†/ } \\
\text { short term }\end{array}$ & 38 & $30.9 \pm 13.3$ & 33 & $31.1 \pm 10.6$ & & $0.0(-0.5$ to 0.4$)$ & & & \\
\hline \multicolumn{12}{|c|}{ Lumbar radicular pain } \\
\hline $\begin{array}{l}\text { Markman et } \\
\text { al. }{ }^{29} \ddagger \ddagger\end{array}$ & $\begin{array}{l}\text { Pregabalin } \\
(300 \mathrm{mg} / \mathrm{d})\end{array}$ & $\begin{array}{c}\text { Pain§/ } \\
\text { immediate term }\end{array}$ & 26 & $7.2 \pm 1.8$ & 26 & $7.0 \pm 1.8$ & 20 & $0.1(-0.4$ to 0.7$)$ & & & \\
\hline $\begin{array}{l}\text { Mathieson et } \\
\text { al. } .^{0}\end{array}$ & $\begin{array}{l}\text { Pregabalin } \\
(600 \mathrm{mg} / \mathrm{d})\end{array}$ & $\begin{array}{c}\text { Pain§/ } \\
\text { immediate term }\end{array}$ & 106 & $4.6 \pm 2.5$ & 97 & $4.9 \pm 2.7$ & 80 & $-0.1(-0.4$ to 0.2$)$ & & & \\
\hline \multicolumn{3}{|c|}{ Pooled effect: $I^{2}=0 \%$} & & & & & 100 & $-0.1(-0.3$ to 0.2$)$ & & & \\
\hline Yildirim et al. ${ }^{34}$ & $\begin{array}{l}\text { Gabapentin } \\
(3600 \mathrm{mg} / \mathrm{d})\end{array}$ & $\begin{array}{c}\text { Pain } 9 / \\
\text { short term§§ }\end{array}$ & 23 & $0.6 \pm 0.6$ & 20 & $1.4 \pm 0.6$ & & $-1.4(-2.0$ to -0.7$)$ & & - & \\
\hline \multirow[t]{3}{*}{$\begin{array}{l}\text { Mathieson et } \\
\text { al. } .^{30}\end{array}$} & $\begin{array}{l}\text { Pregabalin } \\
(600 \mathrm{mg} / \mathrm{d})\end{array}$ & $\begin{array}{c}\text { Pain§/ } \\
\text { short term§§ }\end{array}$ & 100 & $3.7 \pm 2.9$ & 93 & $3.1 \pm 2.6$ & & $0.2(-0.1$ to 0.5$)$ & & & \\
\hline & & $\begin{array}{c}\text { Pain§/ } \\
\text { intermediate term }\end{array}$ & 93 & $3.1 \pm 3.0$ & 91 & $3.2 \pm 2.8$ & & $0.0(-0.3$ to 0.3$)$ & & & \\
\hline & & Pain§/long term & 91 & $3.4 \pm 3.2$ & 87 & $3.0 \pm 2.6$ & & $0.1(-0.2$ to 0.4$)$ & & & \\
\hline $\begin{array}{l}\text { Markman et } \\
\text { al. }{ }^{29} \ddagger \ddagger\end{array}$ & $\begin{array}{l}\text { Pregabalin } \\
(300 \mathrm{mg} / \mathrm{d})\end{array}$ & $\begin{array}{l}\text { Disabilityt†/ } \\
\text { immediate term }\end{array}$ & 26 & $37.8 \pm 14.1$ & 26 & $36.5 \pm 14.1$ & 21 & $0.1(-0.5$ to 0.6$)$ & & & \\
\hline $\begin{array}{l}\text { Mathieson et } \\
\text { al. } .^{30}\end{array}$ & $\begin{array}{l}\text { Pregabalin } \\
(600 \mathrm{mg} / \mathrm{d})\end{array}$ & $\begin{array}{l}\text { Disability } \ddagger / \\
\text { immediate term }\end{array}$ & 101 & $11.7 \pm 6.0$ & 96 & $12.5 \pm 6.3$ & 79 & $-0.1(-0.4$ to 0.1$)$ & & & \\
\hline \multicolumn{3}{|c|}{ Pooled effect: $I^{2}=0 \%$} & & & & & 100 & $-0.1(-0.3$ to 0.2$)$ & & & \\
\hline \multirow[t]{3}{*}{$\begin{array}{l}\text { Mathieson et } \\
\text { al. }{ }^{30}\end{array}$} & $\begin{array}{l}\text { Pregabalin } \\
(600 \mathrm{mg} / \mathrm{d})\end{array}$ & $\begin{array}{l}\text { Disability } \ddagger \ddagger / \\
\text { short term }\end{array}$ & 93 & $9.1 \pm 7.4$ & 89 & $8.5 \pm 7.1$ & & $0.1(-0.2$ to 0.4$)$ & & & \\
\hline & & $\begin{array}{c}\text { Disability } \neq \ddagger / \\
\text { intermediate term }\end{array}$ & 85 & $7.4 \pm 7.4$ & 87 & $8.8 \pm 7.5$ & & $-0.2(-0.5$ to 0.1$)$ & & & \\
\hline & \multicolumn{3}{|c|}{ Topiramate versus placebo } & $8.2 \pm 7.6$ & 79 & $7.4 \pm 7.2$ & & $0.1(-0.2$ to 0.4$)$ & & & \\
\hline \multicolumn{12}{|c|}{ Low back pain with or without radiating leg pain } \\
\hline \multirow[t]{2}{*}{$\begin{array}{l}\text { Muehlbacher et } \\
\text { al. }{ }^{33}\end{array}$} & $\begin{array}{l}\text { Topiramate } \\
(300 \mathrm{mg} / \mathrm{d})\end{array}$ & $\begin{array}{c}\text { Pain**/ } \\
\text { short term }\end{array}$ & 48 & $22.9 \pm 9.7$ & 48 & $34.3 \pm 15.9$ & & $-0.9(-1.3$ to -0.4$)$ & & - & \\
\hline & & $\begin{array}{l}\text { Disabilityt†/ } \\
\text { short term }\end{array}$ & 48 & $34.0 \pm 36.0$ & 48 & $38.9 \pm 36.7$ & & $-0.1(-0.5$ to 0.3$)$ & & & \\
\hline \multicolumn{12}{|c|}{ Lumbar radicular pain } \\
\hline \multirow[t]{4}{*}{$\begin{array}{l}\text { Khoromi et } \\
\text { al. }{ }^{28 \dagger}\end{array}$} & $\begin{array}{l}\text { Topiramate } \\
(400 \mathrm{mg} / \mathrm{d})\end{array}$ & $\begin{array}{c}\text { Pain§/ } \\
\text { immediate term }\end{array}$ & 29 & $3.1 \pm 2.7$ & 29 & $3.8 \pm 2.7$ & & $-0.3(-0.8$ to 0.2$)$ & & & \\
\hline & & $\begin{array}{c}\text { Disability†t/ } \\
\text { immediate term }\end{array}$ & 29 & $25.0 \pm 16.0$ & 29 & $27.0 \pm 15.0$ & & $-0.1(-0.6$ to 0.4$)$ & & & \\
\hline & & & & & & & & & -2.00 & -1.00 & 1.00 \\
\hline & & & & & & & & & & $\begin{array}{r}\text { adized mean } \\
(95 \% \mathrm{Cl})\end{array}$ & lifference \\
\hline
\end{tabular}

Figure 2: Effects on pain and disability of anticonvulsants for low back pain with or without radiating leg pain or lumbar radicular pain. Note: $\mathrm{Cl}=$ confidence interval, immediate term $=$ follow-up evaluations $\leq 2$ weeks after randomization, intermediate term $=$ follow-up evaluations $>3$ months but $<12$ months, long-term $=\geq 12$ months, short-term = follow-up evaluations $>2$ weeks but $\leq 3$ months, SD $=$ standard deviation. ${ }^{*}$ All effect sizes have been converted to standardized mean differences to allow comparison across all outcomes. †Crossover trial. $\ddagger$ Trial investigated neurogenic claudication. §Pain scale 0-10 (numerical pain rating scale). ฯPain scale 0-3. **Pain scale 0-78 (Pain Rating Index). ††Oswestry Disability Index 0-100. ¥łRoland-Morris Disability Questionnaire 0-23. §§The comparison had a very high heterogeneity $\left(I^{2}=95 \%\right)$; therefore, results were not pooled. 
gabapentin in the short term (MD $-0.8,95 \% \mathrm{Cl}-1.2$ to -0.5 on a 0 to 3-point NPRS, $n=43$ participants), Mathieson and colleagues ${ }^{30}$ did not detect an effect in a larger trial (MD 0.6, $95 \% \mathrm{Cl}-0.2$ to 1.4 on a 0 - to 10-point NPRS). Similarly, there was high- and moderatequality evidence of no effect on pain in the intermediate (MD -0.1, $95 \% \mathrm{Cl}-0.9$ to 0.7 on a 0 - to 10 -point NPRS, 1 study ${ }^{30}$ ) or long-term (MD $0.4,95 \% \mathrm{Cl}-0.5$ to 1.3 on a 0 - to 10 -point NPRS, 1 study, ${ }^{30}$ downgraded owing to imprecision), respectively. There was highquality evidence of no effect for disability in the immediate term (pooled SMD $-0.1,95 \% \mathrm{Cl}-0.3$ to $0.2,2$ studies). Disability at all other time points (short-term MD $0.6,95 \% \mathrm{Cl}-1.5$ to 2.7 ; intermediateterm MD $-1.4,95 \% \mathrm{Cl}-3.6$ to 0.8 ; long-term MD $0.8,95 \% \mathrm{Cl}-1.5$ to 3.1, all on a 23-point Roland-Morris Disability Questionnaire) showed no treatment effect, based on a single study, ${ }^{30}$ all with moderate-quality evidence (downgraded owing to imprecision). The fourth study did not provide pain severity or disability data, other than reporting descriptively that no between-group difference was found in disability at the short-term follow-up. ${ }^{27}$

One study investigated topiramate versus placebo for lumbar radicular pain..$^{28}$ There was no treatment effect favouring topiramate in pain (MD $-0.7,95 \% \mathrm{Cl}-2.1$ to 0.6 on a 0 - to 10 -point NPRS) and disability (MD $-2.0,95 \% \mathrm{Cl}-10.0$ to 6.0 on a 100 -point Oswestry Disability Index) in the immediate term. The quality of the evidence was very low for pain (downgraded owing to study design, risk of bias and imprecision) and low for disability (downgraded owing to study design and risk of bias).

\section{Adverse events}

We included data from 7 studies $(n=754),{ }^{26-31,34}$ as 2 studies did not report the numbers of participants who experienced an adverse event ${ }^{32,33}$ (Figure 3). Participants in the crossover studies who received both the anticonvulsant and placebo were counted

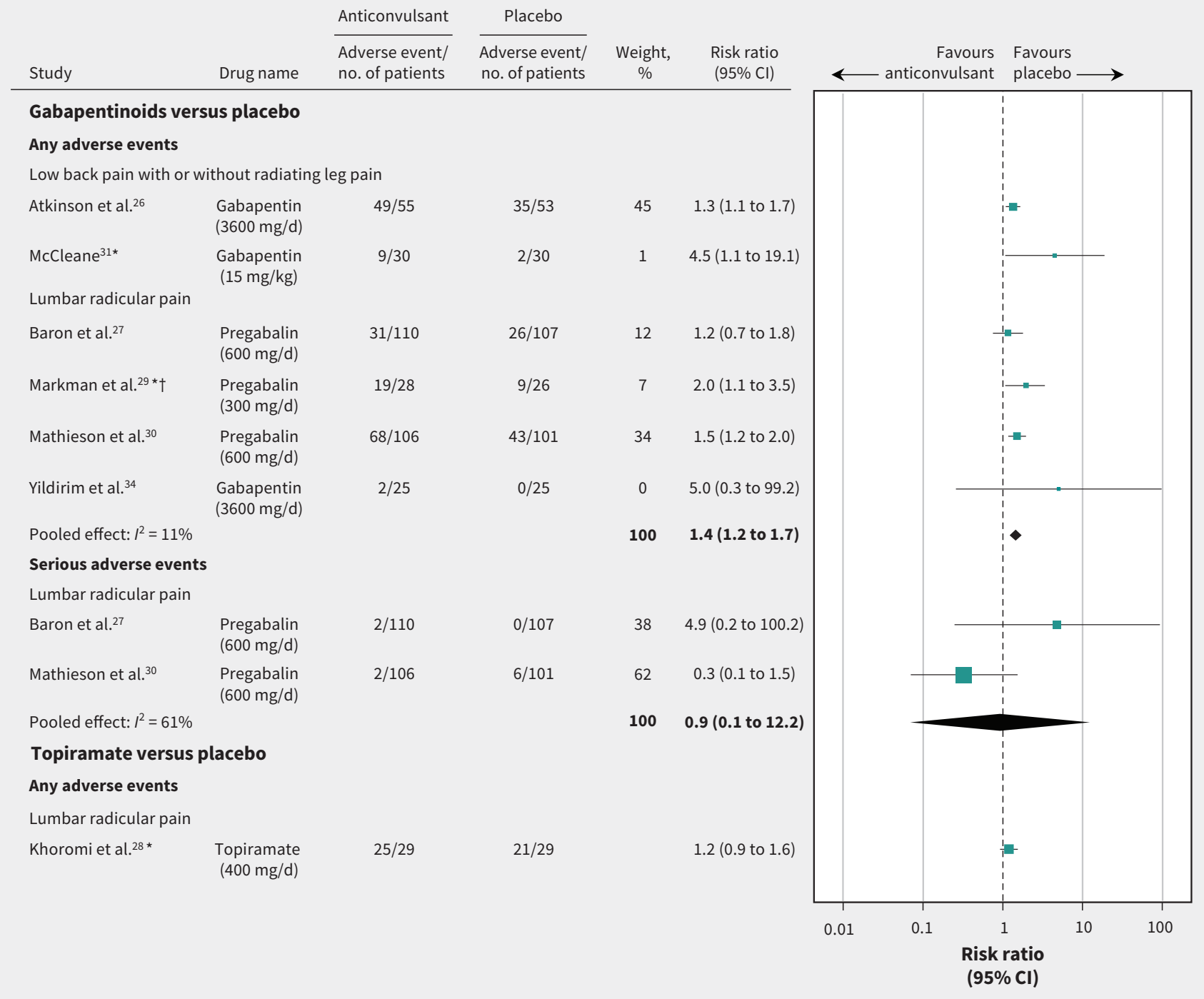

Figure 3: Adverse events with anticonvulsants for low back pain with or without radiating leg pain or lumbar radicular pain. Note: AE = adverse event, $\mathrm{Cl}=$ confidence interval. ${ }^{\star}$ Crossover trial. †Trial investigated neurogenic claudication. 
in each study group..$^{28,29,31}$ Six of the 7 studies investigated the effects of gabapentinoids, ${ }^{26,27,29-31,34}$ with $16.4 \%$ of study participants originating from crossover studies. ${ }^{29,31}$ Pooled results indicate high-quality evidence that gabapentinoids were associated with an increased risk of adverse events compared with placebo (pooled risk ratio [RR] 1.4, 95\% Cl 1.2 to $1.7,6$ studies). One study, which did not report the total numbers of participants experiencing an adverse event, ${ }^{32}$ found a total of 19 adverse events in 31 participants who received gabapentin for chronic low back pain, versus 13 adverse events in 34 participants in the placebo group. The most common adverse events reported in participants taking a gabapentinoid were drowsiness or somnolence, dizziness and nausea (Appendix 6, available at www.cmaj. ca/lookup/suppl/doi:10.1503/cmaj.171333/-/DC1).

Two studies investigated the effects of topiramate. Of these, 1 study ${ }^{28}$ did not find an increased risk of adverse events associated with topiramate (RR $1.2,95 \% \mathrm{Cl} 0.9$ to 1.6 ). However, this study used an active placebo (diphenhydramine) that provided no known treatment effect, but had a similar sedative adverse event profile to topiramate. The quality of evidence was very low (downgraded owing to study design, risk of bias and imprecision). The second study did not report the total number of participants who experienced an adverse event, ${ }^{33}$ but showed 21 adverse events in the topiramate $(n=48)$ and 10 in the placebo $(n=48)$ group.

We planned to analyze serious adverse events and adverse events separately, but only 2 studies made this distinction in their reporting. ${ }^{27,30}$ Both studies compared pregabalin $600 \mathrm{mg} / \mathrm{d}$ versus placebo in patients with lumbar radicular pain. There was no between-group difference in serious adverse events (pooled RR $0.9,95 \% \mathrm{Cl} 0.1$ to 12.2 , moderate-quality evidence, downgraded owing to imprecision).

\section{Other analyses}

For the subgroup analysis, only 1 study included patients with acute and chronic symptoms. ${ }^{30}$ When the effect of pregabalin was analyzed separately for patients with acute and chronic sciatica, there was no treatment effect for pain or disability at all time points for duration of either symptom. The planned sensitivity analysis based on risk of bias was not conducted because of the low number of included studies.

\section{Interpretation}

This systematic review found 9 placebo-controlled randomized trials investigating the effects of anticonvulsants for low back pain and lumbar radicular pain. For chronic low back pain with or without radiating leg pain, there was high-quality evidence showing that gabapentinoids did not reduce pain or disability compared with placebo in the short term, and similarly with lowquality evidence in the intermediate term. There was moderatequality evidence that topiramate provided a small clinically worthwhile effect for pain in the short term, but there was no effect on disability. For lumbar radicular pain, there was generally moderate- to high-quality evidence showing that anticonvulsants had no effect on pain or disability at all time points. For adverse events, there was high-quality evidence showing that gabapentinoids were associated with increased adverse events, and very low-quality evidence showing that topiramate did not increase the risk of adverse events compared with placebo.

For chronic low back pain and neurogenic claudication, similar recent reviews also did not find any treatment benefit for anticonvulsants. ${ }^{5,14}$ Unlike our review, which focuses on comparisons with placebo-controlled trials, Shanthanna and colleagues ${ }^{14}$ compared anticonvulsants with other active treatments for chronic low back pain, and found a small but not clinically worthwhile difference favouring other active treatments (MD 0.4 on a 0 - to 10-point pain scale, $95 \% \mathrm{Cl} 0.20$ to $0.64,3$ studies, very low-quality evidence). Our findings differ from previous evidence on anticonvulsants for lumbar radicular pain, in which a $2012 \mathrm{BMJ}$ review reported a treatment benefit of gabapentin based on a single trial. ${ }^{15}$ One key reason for the difference in our review is the inclusion of a 2017 study that found pregabalin was no more effective than placebo in patients with sciatica. ${ }^{30}$

Clinically, the prescription of anticonvulsants for back and neck pain, including radicular pain in primary care, has increased by $535 \%$ in the last 10 years. ${ }^{36}$ This trend may be due to prescribers seeking an alternative to opioids. ${ }^{37}$ We have shown, with mostly high- and moderate-quality evidence, that common anticonvulsants are ineffective for chronic low back pain and lumbar radicular pain, and are accompanied by increased risk of adverse events. Our findings are in line with recent United States and United Kingdom guidelines for low back pain, ${ }^{6,7}$ which do not recommend the use of anticonvulsants. Regarding sciatica, the 2016 UK guideline recommends following neuropathic pain guidelines, ${ }^{6}$ which endorse the use of gabapentinoids. ${ }^{38}$ However, the recommendation of gabapentinoids for sciatica should be reviewed in light of emerging evidence.

\section{Limitations}

This prospectively registered review used a sensitive search strategy with no limitation on language or publication type. All but 1 included trial ${ }^{28}$ had low risk of bias and most studies provided adequate data that could be integrated into a metaanalysis. The meta-analysis separated results by pain type and anticonvulsant drug and included the most complete selection of all available placebo-controlled studies on this topic and accurate effect size estimates. We acknowledge, however, that the initial title and abstract screening was performed by 1 author, but full-text screening and data management involved at least 2 authors. The current body of evidence is small, as only 3 anticonvulsants (gabapentin, pregabalin and topiramate) were included, and only 1 trial included patients with acute symptoms. ${ }^{30}$ We chose to include only placebo-controlled trials to investigate efficacy, but future reviews could include activecontrolled trials as well. Some evidence is based on single-trial results; thus, some results show imprecision owing to wide effect size distribution.

\section{Conclusion}

Evidence to date does not support the use of anticonvulsants for chronic low back pain or lumbar radicular pain. This review found mostly moderate- to high-level quality of evidence suggesting no treatment benefit for pain and disability, and highlevel evidence supporting the risk of harms. 


\section{References}

1. Hoy D, March L, Brooks P, et al. The global burden of low back pain: estimates from the Global Burden of Disease 2010 study. Ann Rheum Dis 2014;73:968-74.

2. Koes BW, van Tulder MW, Peul WC. Diagnosis and treatment of sciatica. BMJ 2007;334:1313-7.

3. Ropper AH, Zafonte RD. Sciatica. N Engl J Med 2015;372:1240-8.

4. Chou R, Qaseem A, Snow V, et al.; Clinical Efficacy Assessment Subcommittee of the American College of Physicians; American College of Physicians; American Pain Society Low Back Pain Guidelines Panel. Diagnosis and treatment of low back pain: a joint clinical practice guideline from the American College of Physicians and the American Pain Society. Ann Intern Med 2007;147:478-91.

5. Chou R, Deyo R, Friedly J, et al. Systemic pharmacologic therapies for low back pain: a systematic review for an American College of Physicians clinical practice guideline. Ann Intern Med 2017;166:480-92.

6. Low back pain and sciatica in over 16s: assessment and management. NICE guideline (NG59). London (UK): National Institute for Health and Care Excellence; 2016. Available: www.nice.org.uk/guidance/ng59 (accessed 2017 Sept. 9).

7. Qaseem A, Wilt TJ, McLean RM, et al.; Clinical Guidelines Committee of the American College of Physicians. Noninvasive treatments for acute, subacute, and chronic low back pain: a clinical practice guideline from the American College of Physicians. Ann Intern Med 2017;166:514-30.

8. Mafi JN, McCarthy EP, Davis RB, et al. Worsening trends in the management and treatment of back pain. JAMA Intern Med 2013;173:1573-81.

9. Arana A, Wentworth CE, Ayuso-Mateos JL, et al. Suicide-related events in patients treated with antiepileptic drugs. N Engl J Med 2010;363:542-51.

10. Chiappini S, Schifano F. A decade of gabapentinoid misuse: an analysis of the European Medicines Agency's 'Suspected Adverse Drug Reactions' database. CNS Drugs 2016;30:647-54

11. Stannard C. Misuse of gabapentin and pregabalin: a marker for a more serious malaise? Addiction 2016;111:1699-700.

12. Maizels M, McCarberg B. Antidepressants and antiepileptic drugs for chronic noncancer pain. Am Fam Physician 2005;71:483-90.

13. Wiffen PJ, Derry S, Moore RA, et al. Antiepileptic drugs for neuropathic pain and fibromyalgia - an overview of Cochrane reviews. Cochrane Database Syst Rev 2013;(11):CD010567.

14. Shanthanna H, Gilron I, Rajarathinam M, et al. Benefits and safety of gabapentinoids in chronic low back pain: a systematic review and meta-analysis of randomized controlled trials. PLoS Med 2017;14:e1002369.

15. Pinto RZ, Maher CG, Ferreira ML, et al. Drugs for relief of pain in patients with sciatica: systematic review and meta-analysis. BMJ 2012;344:e497.

16. ATC/DDD Index N03A - Updates included in the ATC/DDD Index. Oslo (Norway): WHO Collaborating Centre for Drug Statistics Methodology; 2015 (updated 2017 Dec. 20). Available: www.whocc.no/atc_ddd_index/?code=N03A (accessed 2017 Sept. 9).

17. Updated search strategies for Cochrane Back Review Group. Toronto: Cochrane Back and Neck; 2011. Available: http://back.cochrane.org/sites/back.cochrane. org/files/uploads/PDF/CBRG_searchstrat_Jun2011.pdf (accessed 2017 Sept. 9).

18. Price M, Günther A, Kwan JS. Antiepileptic drugs for the primary and secondary prevention of seizures after intracranial venous thrombosis. Cochrane Database Syst Rev 2016;4:CD005501.

19. Higgins JPT, Green S, editors. Cochrane Handbook for Systematic Reviews of Inter- ventions Version 5.1.0. Oxford (UK): The Cochrane Collaboration; 2011 (updated March 2011). Available: http://handbook.cochrane.org (accessed 2018 Mar. 8).

20. Maher CG, Sherrington C, Herbert RD, et al. Reliability of the PEDro scale for rating quality of randomized controlled trials. Phys Ther 2003;83:713-21.

21. Yamato TP, Maher C, Koes B, et al. The PEDro scale had acceptably high convergent validity, construct validity and inter-rater reliability in evaluating methodological quality of pharmaceutical trials. J Clin Epidemiol 2017;86:176-81.

22. de Morton NA. The PEDro scale is a valid measure of the methodological quality of clinical trials: a demographic study. Aust J Physiother 2009;55:129-33.

23. Schmidt PC, Ruchelli G, Mackey SC, et al. Perioperative gabapentinoids: choice of agent, dose, timing, and effects on chronic postsurgical pain. Anesthesiology 2013;119:1215-21.

24. Ferreira ML, Herbert RD, Ferreira PH, et al. The smallest worthwhile effect of nonsteroidal anti-inflammatory drugs and physiotherapy for chronic low back pain: a benefit-harm trade-off study. J Clin Epidemiol 2013;66:1397-404.

25. Guyatt GH, Oxman AD, Vist GE, et al.; GRADE Working Group. GRADE: an emerg ing consensus on rating quality of evidence and strength of recommendations. BMJ 2008;336:924-6.

26. Atkinson JH, Slater MA, Capparelli EV, et al. A randomized controlled trial of gabapentin for chronic low back pain with and without a radiating component. Pain 2016;157:1499-507.

27. Baron R, Freynhagen R, Tolle TR, et al.; A0081007 Investigators. The efficacy and safety of pregabalin in the treatment of neuropathic pain associated with chronic lumbosacral radiculopathy. Pain 2010;150:420-7.

28. Khoromi S, Patsalides A, Parada S, et al. Topiramate in chronic lumbar radicular pain. J Pain 2005;6:829-36.

29. Markman JD, Frazer ME, Rast SA, et al. Double-blind, randomized, controlled, crossover trial of pregabalin for neurogenic claudication. Neurology 2015;84:265-72.

30. Mathieson S, Maher CG, McLachlan AJ, et al. Trial of pregabalin for acute and chronic sciatica. N Engl J Med 2017;376:1111-20.

31. McCleane GJ. Gabapentin reduces chronic benign nociceptive pain: A doubleblind, placebo-controlled cross-over study. Pain Clin 2000;12:81-5.

32. McCleane GJ. Does gabapentin have an analgesic effect on background, movement and referred pain? A randomised, double-blind, placebo controlled study. Pain Clin 2001;13:103-7.

33. Muehlbacher M, Nickel MK, Kettler C, et al. Topiramate in treatment of patients with chronic low back pain: a randomized, double-blind, placebo-controlled study. Clin J Pain 2006;22:526-31.

34. Yildirim K, Şışecıoğlu M, Karatay S, et al. The effectiveness of gabapentin in patients with chronic radiculopathy. Pain Clin 2003;15:213-8.

35. Australian Medicines Handbook. Adelaide (Australia): Australian Medicines Handbook Pty Ltd.; 2017. Available: https://amhonline.amh.net.au/ (accessed 2017 Sept. 9). Login required to access content.

36. Mathieson S, Valenti L, Maher CG, et al. Worsening trends in analgesics recommended for spinal pain in primary care. Eur Spine J 2018;27:1136-45.

37. Goodman CW, Brett AS. Gabapentin and pregabalin for pain - Is increased prescribing a cause for concern? N Engl J Med 2017;377:411-4.

38. Neuropathic pain in adults: pharmacological management in non-specialist settings. NICE guideline (CG173). London (UK): National Institute for Health and Care Excellence; 2017. Available: www.nice.org.uk/guidance/cg173 (accessed 2017 Sept. 9).
Competing interests: Stephanie Mathieson, Andrew McLachlan, Jane Latimer, Christopher Maher and C.-W. Christine Lin were investigators on the included PRECISE study, which was an investigator-initiated trial evaluating pregabalin for sciatica, funded by the National Health and Medical Research Council of Australia with in-kind research support from Pfizer (ACTRN12613000530729). These authors did not contribute to any data management regarding this study for this review. Christopher Maher reports receiving a grant from Pfizer, outside the submitted work; Andrew McLachlan reports receiving a grant from GlaxoSmithKline Australia. No other competing interests were declared.

This article has been peer reviewed.

Affiliations: The University of Sydney (Enke, H.A. New, C.H. New), Sydney Medical School Nepean, Kingswood, Australia; Westmead Hospital (H.A.
New), Westmead, Australia; The University of Sydney (Mathieson, Latimer, Maher, Lin), Sydney School of Public Health; The University of Sydney and Concord Hospital (McLachlan), Faculty of Pharmacy and Centre for Education and Research on Ageing, Sydney, Australia

Contributors: Oliver Enke had full access to all the data in the study, and takes responsibility for the integrity of the data and the accuracy of the data analysis. Oliver Enke, Heather New, Charles New, Stephanie Mathieson, Christopher Maher and C.-W. Christine Lin were involved in the design of the review. Andrew McLachlan advised on the review protocol and on pharmacologic questions. Oliver Enke, Charles New and C.-W. Christine Lin developed the search strategy. Oliver Enke performed the initial study selection. Oliver Enke, Heather New, Charles New, Stephanie Mathieson and C.-W. Christine Lin extracted data from included studies. Oliver Enke, Stephanie
Mathieson, Jane Latimer, Christopher Maher and C.-W. Christine Lin were involved in data analysis, interpretation and discussion of results. All authors contributed to supervising the conduct of the study and data collection, and to drafting or revising the manuscript. All authors gave final approval of the version to be published and agree to be accountable for all aspects of the work.

Funding: This research project did not receive any external funding. Two authors (Christopher Maher, C.-W. Christine Lin) are funded by fellowships from the National Health and Medical Research Council of Australia. Andrew McLachlan is the Program Director of the NHMRC Centre for Research Excellence on Medicines and Ageing.

Accepted: Apr. 11, 2018

Correspondence to: Oliver Enke, dr.oliver.enke@gmail.com 